\title{
Early Experience with Low Profile Plate Osteosynthesis for Metacarpal Fractures
}

\author{
J oshi $A,{ }^{1} \mathrm{KC} B R,{ }^{1}$ Chand $\mathrm{P},{ }^{1}$ Thapa $\mathrm{BB}^{1}$ \\ 1Department of Orthopedics, Shree Birendra Hospital, Kathmandu, Nepal
}

\begin{abstract}
Background: Among various fixation methods for metacarpal fractures, plate osteosynthesis is the most rigid and allows early rehabilitation leading to early return to work. Many authors have reported high complication rates and most of them were because of thick plate. The aim of this study was to report early results of plate osteosynthesis of metacarpal fractures with low profile miniplate.

Methods: This was a hospital based prospective study. Unstable and irreducible fractures were managed by open reduction and internal fixation with low profile miniplate and were followed up for 6 months. The functional outcome after fracture treatment was assessed by ability to perform acts of daily life and calculating American Society for Surgery of the Hand Total Active Flexion (ASSH TAF) score.

Results: There were 16 patients with 17 metacarpal fractures, $87.5 \%$ were male with mean age of $31.50 \pm 9.02$ years. Fourteen $(87.5 \%)$ patients could perform their activities of daily living at four weeks. The mean Total Active Flexion was $261.76 \pm 24.87$ at final follow up. Fourteen (87.5\%) patients had excellent, one (6.25\%) good and one (6.25\%) poor out come at the end of 6 months.

Conclusion: Low severity metacarpal fractures can be treated successfully by open reduction internal fixation with low-profile miniplate, allowing early and safe mobilization.

Key words: low-profile plate, metacarpal fractures, plate osteosynthesis
\end{abstract}

\section{INTRODUCTION}

Majority of metacarpal fractures are amenable to conservative treatment with external immobilization and subsequent rehabilitation. ${ }^{1}$ Unstable fracturesare difficult to treat, and the results are not always satisfactory. ${ }^{2-4}$ Several authors have stressed the importance of rigid fixation, and concluded that plate and screws is ideal to serve this purpose. ${ }^{5-10}$ Biomechanical studies have consistently shown that a dorsally applied plate provides the greatest rigidity; therefore this fixation technique has become the most common method of open reduction and internal fixation for displaced, unstable metacarpal fractures. ${ }^{11,12}$ Sufficient rigidity helps to ensure timely fracture healing and to allow earlier and more intensive digital rehabilitation, which is the mainstay of good functional outcome.

The majority of papers looking at this subject have included both metacarpal and phalangeal fractures and reported higher complication rate. 4,13,14 Most of these complications were associated with thick plates and was more pronounced in phalangeal rather than metacarpal fractures. The aim of our study was to evaluate the functional results after closed and extra-articular metacarpal fractures treated by low profile plates and screws.

Correspondence: Dr. Amit J oshi, Department of Orthopedics. Shree Birendra Hospital, Kathmandu, Nepal. Phone: 9841233850, Email: dramitjoshi7@gmail. com 
Early Experience with Low Profile Plate Osteosynthesis for Metacarpal Fractures

\section{METHODS}

A prospective hospital based study was conducted at Shree Birendra Hospital, Nepal, for a period of two years (J uly 2006 to August 2008). Only unstable, irreducible and displaced fractures were enrolled, excluding open fractures, intraarticular fractures, younger patients (less than 14 years), and diabetics. The ethical approval and informed written consent was taken. Total 17 patients with 19 metacarpal fractures (two patients had two metacarpal fractures each) were treated at our institution by open reduction and internal fixation (ORIF) with miniplate and screws. The characteristics of plate and screws are given in box 1 .

All operations were performed with a pneumatic tourniquet bandage in upper arm. A dorsal approach was used and access to the bone was achieved by retracting the extensor tendons ulnarly or radially. The periosteal sleeve was also opened longitudinally and the bone exposed subperiosteally to visualize the fracture. The fracture was then reduced by longitudinal traction on the digit, and the reduction was held in compression by a towel clip. Fixation was achieved with plate and screws according to the standard $\mathrm{AO}$ technique with minimum of four cortices in each side of fracture (see figure $4 \mathrm{a}, \mathrm{b}, \mathrm{c}$ ). The periosteal sleeve was closed over the plate and wound closed in layers. Postoperatively, elastic bandage was applied and exercises were started after 2-3 days by the patient him/herself following a physiotherapist's instructions.

The patients were followed up at 2 weeks, 4 weeks, 8 weeks, 3 months and finally at 6 months for clinical and functional evaluation. The functional outcome after fracture treatment was assessed by ability to perform acts of daily life (writing, drinking, shaking hands, combing, opening cap of a bottle, button own shirt, brushing and washing face) and calculating ASSH TAF (American Society for Surgery of the Hand Total Active Flexion) score at each follow up. ${ }^{15}$

Patients were requested to perform above mentioned acts of daily life (ADL) at the time of follow up. TAF (Total Active Flexion) was calculated by adding the active flexion at metacarpophalangeal, proximal interphalangeal and distal interphalangeal joints (See figure $4 \mathrm{~d}, \mathrm{e}, \mathrm{f}, \mathrm{g}$ ). Patients with $\leq 120^{\circ}$ of ASSH TAF score are classified as poor: $121^{\circ}-220^{\circ}$ as good; and $\geq 221$ as excellent.

Radiographs were taken to evaluate bony union at 1 and 3 months and as per requirement if there is delayed union. Data were analyzed using statistical packages for social sciences (SPSS) version 11.5 for windows. Chi-square and t-test were applied for testing statistical significance wherever applicable and the level of significance was set as $p \varangle 0.05$.

\section{RESULTS}

Initially we had 17 patients with 19 metacarpal fractures (two patients had double metacarpal fractures) operated. One patient with double ( $\mathrm{V}^{\text {th }}$ and $\mathrm{V}^{\text {th }}$ ) Metacarpal fracture (Figure 1), sustained re injury of the same hand and bend his plates. This patient refused to participate further in the study, so for final analysis we had 16 patients with 17 metacarpal fractures.

The mean age of the patient was $31.50 \pm 9.02$ years (range 20-54 years). Fourteen (87.5\% patients out of 16 fell in age group of 20-40 years. Majority of our patients were male $(87.5 \%)$ with male female ratio of $7: 1$. The IVth Metacarpal was most commonly involved (47.1\%), followed by $\mathrm{III}^{\text {rd }}(29.4 \%), \mathrm{V}^{\text {th }}(17.6 \%)$ and $\mathrm{II}^{\text {nd }}(5.9 \%)$. Oblique fracture was the most commonly observed fracture in 8 (47.1\%) patients followed by spiral in 6 (35.3\%) and transverse in $3(17.6 \%)$. The demographic and clinical data are presented in table 1.

Eight (50\%) patients were able to perform ADL at two weeks which increased to $87.5 \%(14 / 16)$ at 1 month follow up. Two patients who had developed Reflex sympathetic dystrophy (RSD) could perform their complete ADL at 3 months follow up.

The TAF improved in successive follow-up, it was $240.59 \pm 36.82$ at 3 month and $261.76 \pm 24.87$ at the end of 6 months. At three months, mean TAF was significantly lower in comparison to the normal ray $(p=0.002)$, although ASSG TAF was excellent $\left(>220^{\circ}\right)$. The mean TAF of operated ray improved to $261.76 \pm 24.87$ at 6 month, which was not significantly different $(p=0.06)$ from that of normal ray $(272.94 \pm 4.69)$. According to ASSH TAF scoring system, 13 (81.25\%) patients had excellent, $12.5 \%$ Good and $6.25 \%$ poor outcome at three months follow-up which improved to $87.5 \%$ (14) excellent, $6.25 \%$ (1) good and $6.25 \%$ (1) poor outcome at the end of 6 months. Three (18.75\%) patient developed complications, $12.5 \%$ (2) had Reflex sympathetic dystrophy and 6.25\%(1) had hypertrophied surgical scar. We had one case of implant failure, bend implant after re inj ury, which was excluded from our study, as he refused to participate further.

\section{DISCUSSION}

Hand and upper extremity injuries are one of the most common injuries treated in emergency departments. ${ }^{16}$ Fractures of the phalanges and metacarpals account for $10 \%$ of all fractures and it account for at least $41 \%$ of all fractures of the upper extremity. ${ }^{17}$ Early techniques of splint immobilization worked well for simple hand fractures, but fell short in more complex inj uries. The list of techniques described for treatment of these fracture is exhaustive. Whatever technique is used, principles of fracture management remain the same, with goal to 
restore full hand function. As a general rule, this can be accomplished through anatomic reduction, obtaining adequate stability to allow early range of motion. The use of percutaneously inserted wires has remained a mainstay of the treatment of hand fracture till date. In the developing world like Nepal, where intraoperative image intensifier is not readily available to guide wire placement, this procedure is difficult to perform. ${ }^{18}$ Plate fixation has advantage of rigid fixation which allows earlier rehabilitation and return to work, and since open reduction is performed it does not require image intensification. Interest in plate fixation of hand fractures stems from the biomechanical studies of Fyfe and Mason and Massengill et al. 8,10 Their study showed that plates and screws provided rigid stabilization that would permit early motion, which hopefully would minimize the stiffness and tendon adhesions that result from immobilization. ${ }^{3,19}$ Biomechanical studies have consistently shown that a dorsally applied plate provides the greatest rigidity in apex dorsal bending (for most fracture types); this fixation technique has therefore become the most common method of open reduction internal fixation for displaced, unstable metacarpal fractures. ${ }^{11,12}$

Although our sample size is very small to come to a conclusion regarding demographic results, they are very much similar to many studies published earlier. The 7:1 male:female ratio in our series is higher than many of previously published studies, but was similar to that of Margic's prospective study of one hundred consecutive patients. ${ }^{20-23}$ The male predominance in our series is because this study was performed at military hospital, and in Nepalese army females are very few in numbers. Almost $90 \%$ of our patients fell in age group of 20-40 years. Higher incidence in this age group have economic impact which is directly proportional to time of immobilization. Speedy recovery and early return to work becomes doubly important in military population, as they have to undergo many trainings for their future career. Higher incidence in this age group was also reported by Onselen and Stanton. ${ }^{20,23}$

Although fracture of the Vth metacarpal is the commonest at any age group, they have higher tolerance to displacement and angulations, so most of them are managed conservatively. This is the reason why only $18 \%$ of this study had fracture of Vth metacarpal. In our study fracture of IVth and IIIrd metacarpals were the commonest, which was similar to Trevisan's series. ${ }^{21}$

Not many authors have evaluated ADL in their studies, which we think is an important parameter of functional outcome. ADL is even more important as majority of metacarpal fractures occurs in the dominant hand. Fourteen (87.5\%) patients could perform ADL at 4 weeks, was similar to that of Travesian's series (29.6 days). ${ }^{21}$ Twelve (75\%) patients were able to do demanding work (at preinjury level) at 8 weeks and $94 \%$ were able to do so by 3 months.

In our study $87.5 \%$ (14) had excellent, $6.25 \%$ (1) good and $6.25 \%(1)$ poor outcome at the end of 6 months, these results were comparable to similar studies (Table 2 ). Although the ASSH TAF score was excellent $\left(>220^{\circ}\right)$ from 8 weeks onwards, the mean TAF was significantly lower $(p=0.002)$ till 3 months follow up. But, there was no significant difference in mean TAF of injured and normal ray at 6 months.

We have lower complication rates in comparison to many studies (Table 3). Most of the complications in previous studies were related to thickness of implant and severity of soft tissue injury. Although our study had very small sample size to compare with these studies, lower complication rates may be because of low profile of the plate and careful handling of the tissue and closure of periosteum over the plate. One another aspect is that, majority of these studies have included phalangeal fractures along with metacarpal. We agree to the fact that plate fixation for phalangeal fracture causes more tissue damage leading to poor outcome, but plate osteosynthesis for metacarpal fractures has better scope and its excellent outcome should not be undermined by the poor outcome of phalangeal fractures. Two of our patients have developed reflex sympathetic dystrophy (RSD), which has compromised the TAF and functional outcome. It is difficult to explain RSD occurred because of surgery or it would have been there even if managed conservatively. The incidence of RSD followed by hand injury is higher than that we had in this series.

One of our patients had bent his plate when he fell down on the fractured hand 4 weeks after surgery (Figure 1). Only Trevisan has mentioned one case of asymptomatic hardware breakage, other wise no such complication has been mentioned in reviewed literatures. ${ }^{21}$ Bend plate may be because of its low profile with low bending rigidity. Protection after surgery in less compliant patients can be considered.

\section{CONCLUSION}

Although closed reduction and percutaneous pinning with K-wires holds theoretical advantages over open reduction and internal fixation, favorable outcomes can be expected by low profile plate osteosynthesis in lowseverity metacarpal fractures.

Box 1. Characteristics of plate and screw

$\begin{array}{ll}\text { Width of plate } & =5.5 \mathrm{~mm} \\ \text { Profile(thickness) } & =1 \mathrm{~mm} \\ \text { Core diameter of screw } & =1.7 \mathrm{~mm} \\ \text { Thread diameter of screw } & =2 \mathrm{~mm} \\ \text { Drillbit used } & =1.5 \mathrm{~mm}\end{array}$


Early Experience with Low Profile Plate Osteosynthesis for Metacarpal Fractures

\begin{tabular}{|c|c|c|c|c|c|c|c|c|}
\hline Case no. & Age & Sex & Metacarpal & $\begin{array}{l}\text { Fracture } \\
\text { morphology }\end{array}$ & $\begin{array}{l}\text { TAF at } 6 \\
\text { Months }\end{array}$ & $\begin{array}{ll}\text { ASSH } & \text { TAF } \\
\text { Score } & \end{array}$ & $\begin{array}{l}\text { TAF of } \\
\text { normal Ray. }\end{array}$ & Complication \\
\hline 1 & 22 & M & IV & Oblique & 260 & Excellent & 270 & \\
\hline 2 & 36 & M & III & Oblique & 270 & Excellent & 270 & \\
\hline 3 & 54 & $M$ & IV & Spiral & 270 & Excellent & 270 & \\
\hline 4 & 21 & M & IV & Transverse & 180 & Poor & 270 & RSD \\
\hline 5 & 20 & $M$ & IV & Spiral & 260 & Excellent & 270 & \\
\hline 6 & 28 & M & V & Oblique & 270 & Excellent & 270 & \\
\hline 7 & 26 & M & V & Spiral & 280 & Excellent & 280 & Hypertrophied scar \\
\hline 8 & 31 & $M$ & ॥ & Transverse & 270 & Excellent & 270 & \\
\hline 9 & 40 & $\mathrm{~F}$ & IV & Spiral & 280 & Excellent & 280 & \\
\hline 10 & 38 & M & III & Oblique & 270 & Excellent & 270 & \\
\hline 11 & 26 & $M$ & $\begin{array}{l}\text { IV } \\
\text { III }\end{array}$ & $\begin{array}{l}\text { Transverse } \\
\text { Spiral }\end{array}$ & $\begin{array}{l}275 \\
220\end{array}$ & Good & $\begin{array}{l}280 \\
270\end{array}$ & RSD \\
\hline 12 & 24 & M & III & Spiral & 270 & Excellent & 280 & \\
\hline 13 & 32 & $\mathrm{~F}$ & III & Oblique & 270 & Excellent & 280 & \\
\hline 14 & 42 & M & IV & Oblique & 270 & Excellent & 270 & \\
\hline 15 & 34 & M & IV & Oblique & 265 & Excellent & 270 & \\
\hline \multirow[t]{2}{*}{16} & 30 & M & V & Oblique & 270 & Excellent & 270 & \\
\hline & $\begin{array}{l}\text { Mean } \\
\text { a g e } \\
=31.5\end{array}$ & $\begin{array}{l}M=14 \\
F=2\end{array}$ & $\begin{array}{l}\|=1 \\
I I I=5 \\
I V=8 \\
V=3\end{array}$ & $\begin{array}{l}\mathrm{Tr}=8 \\
\mathrm{Ob}=6 \\
\mathrm{Sp}=3\end{array}$ & $\begin{array}{l}\text { M e a } \mathrm{n} \\
\mathrm{TAF}= \\
261.76\end{array}$ & $\begin{array}{l}E=14 \\
G=1 \\
P=1\end{array}$ & $\begin{array}{l}\text { Mean TAF = } \\
272.94\end{array}$ & \\
\hline
\end{tabular}

\section{Table 2. Comparisons with similar studies}

\begin{tabular}{|c|c|c|}
\hline Study & No. of Metacarpals & Results \\
\hline Trevisan ${ }^{21}$ & 45 & Excellent-good 45 \\
\hline Mergic ${ }^{22}$ & 37 & Excellent - 34, Good - 3 \\
\hline Steven ${ }^{24}$ & 63 & Excellent - 39, Good - 9, Fair - 8, Poor - 7 \\
\hline Knopp 25 & 146 & Excellent to good $-81.5 \%$ Satisfactory $-14.8 \%$ Poor $-3.7 \%$ \\
\hline Dumont ${ }^{26}$ & 14 & Excellent - Good 12, Poor - 2 \\
\hline Bosscha $^{27}$ & 34 & Excellent - 31 \\
\hline Agrawal ${ }^{28}$ & 17 & Excellent - 8, Good - 7, Poor - 2 \\
\hline Souer ${ }^{29}$ & 19 & Excellent - 18 \\
\hline Nalbantoglu ${ }^{30}$ & 43 & Excellent - 25, Good - 12, Fair - 5, Poor - 1 \\
\hline Our study & 16 & Excellent - 14, Good - 1, Poor - 1. \\
\hline
\end{tabular}

\section{Table 3. Comparision of complication rates}

\begin{tabular}{|lccccc|}
\hline Study & Sample size & Minor complications & Maj or complications & Total & $\%$ \\
\hline Trevisan $^{21}$ & 45 & 11 & 3 & 14 & 31 \\
Steven $^{24}$ & 63 & 17 & 15 & 32 & 50.79 \\
Fusetti $^{31}$ & 129 & 21 & 7 & 28 & 35 \\
Nalbantoglu $^{30}$ & 43 & $\mathrm{n} / \mathrm{m}$ & 10 & 10 & 23 \\
Our study & 16 & 3 & 0 & 3 & 18.75 \\
\hline \hline
\end{tabular}




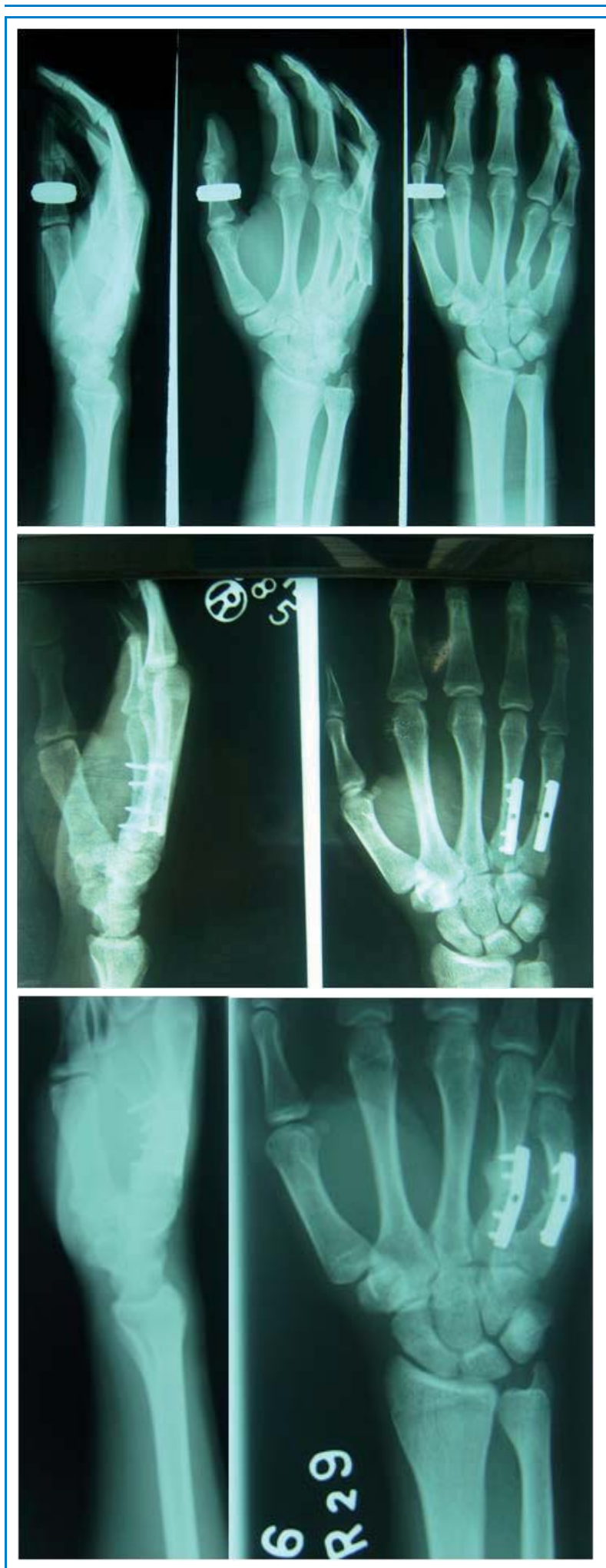

Figure 1. Bent implant after re injury

a. Preoperative X-Ray. b. immediate postoperative XRay c. Bending of plate after re injury.
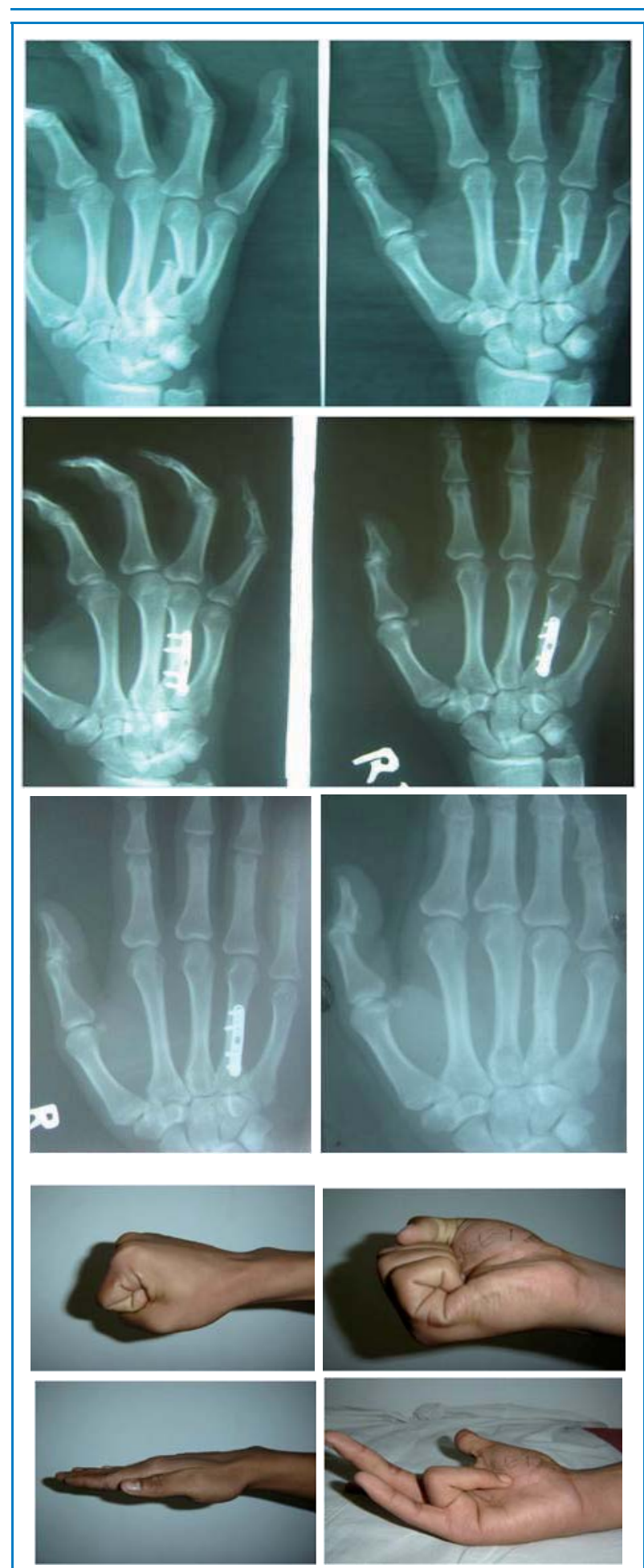

Figure 2. Illustration of case 4

a. fracture of IV $V^{\text {th }}$ Metacarpal. b. Fixed with low profile miniplate with four cortices each side. c. fracture united at 3 month followup. d. implant removed after 6 months. e,f,g, h: TAF calculation. 
Early Experience with Low Profile Plate Osteosynthesis for Metacarpal Fractures

\section{REFERENCES}

1. Prokop A, Helling HJ, Kulus S, Rehm KE. Conservative treatment of metacarpal fracture. Kongressbd Dtsch Ges Chir Kongr 2002;119:532-535.

2. Chow SP, Pun WK, So YC, Luk KDK, Chiu KY, Ng KH, Ng C, Crosby CA. Prospective study of 245 open digital fractures of the hand. J Hand Surg (Br) 1991;16:137-140.

3. Hastings H. Unstable metacarpal and phalangeal fracture treatment with screws and plates. Clin Orthop 1987;214:37-52.

4. Pun WK, Chow SP, So YC et al. Unstable phalangeal fractures: treatment by A.O. screw and plate fixation. J Hand Surg (Am) 1991;16:113-117.

5. Freeland AE, Geissler WB, Weiss AP. Operative treatment of common displaced and unstable fractures of the hand. J Bone Joint Surg (Am) 2001;83:928-945.

6. James JIP. Fractures of the proximal and middle phalanges of the finger. Acta Orthop Scand 1962;32:401-412.

7. RuediTP, Burri C, Pfeiffer KM. Stable internal fixation of fractures of the hand. JTrauma 1971;11:381-389.

8. Fyfe IS, Mason S. The mechanical stability of internal fixation of fractured phalanges. Hand 1979;11:50-54.

9. Mann RJ, Black DM, Constine RM, Daniels AU. A quantitative comparison of metacarpal fracture stability with five different methods of internal fixation. J Hand Surg (Am) 1985;10:10241028 .

10. Massengil JE, Alexander H, Lagrana N, Mylod AA. Phalangeal fracture model-quantitative analysis of rigidity and failure. J Hand Surg (Am) 1982;17:264-270.

11. Firoozbakhsh KK, Moneim MS, HoweyT, Castaneda E, Pirela-Cruz MA. Comparative fatigue strengths and stabilities of metacarpal internal fixation techniques. J Hand Surg(Am) 1993;18A:10591068 .

12. Jones WW. Biomechanics of small bone fixation. Clin Orthop 1987;214:11-18

13. Chen SHT, Wie F, Chen H, Chuang C, Noordhoff S. Miniature plates and screws in acute complex hand injury. J Trauma 1994;37:237-242.

14. Stern PJ, Wieser MJ, Reilly DG. Complications of plate fixation in the hand skeleton. Clin Orthop 1987;214:59-65.

15. Freeland AE. Outcome determinants in Hand fractures - Repair, Reconstruction and Rehabilitation. Philadelphia: Churchill livingstone; 2000. p. 11-13.

16. Emmett JE, Breck LW. A review of analysis of 11,000 fractures seen in a private practice of orthopaedic surgery. J Bone Joint Surg(Am) 1958;40A:1169-1175.
17. Chung KC, Spilson SV. The frequency and epidemiology of hand and forearm fractures in the United States. J Hand Surg (Am) 2001;26:908-915.

18. Bernstein ML, Chung CK: Hand fracture and their management: Injury 2006;37:1043-1048.

19. Jabaley ME, Freeland AE. Rigid internal fixation in the hand: 104 cases. Plast Reconstr Surg 1986;77:288-297.

20. Stanton JS, Dias JJ, Burke FD. Fracture of the tubular bones of the hand. J hand $\operatorname{surg}(\mathrm{Eu})$ 2007;32(6):626-636.

21. Trevisan C, Morganti A, Casiraghi A, Mannini CE. Low severity metacarpal and phalangeal fractures treated with miniature plates and screws. Arch Orthop Trauma Surg 2004;124:675-680.

22. Margic K. External fixation of closed metacarpal and phalangeal fractures of digits: A prospective study of one hundred consecutive patients. J hand surg (Br) 2006;31(1):30-40.

23. Onselen VEBH, Karim RB, Hage JJ, Ritt MJPF. Prevalence and distribution of hand fractures. J Hand Surg (Br) 2003;28(5):491495.

24. Steven MP, Peter JS, Cincinnati OH. Complication and range of motion following plate fixation of metacarpal and phalangeal fractures. J Hand Surg(Am) 1998;23:827-832.

25. Knopp W, Nowak B, Buchholz J, Muhr G, Rehn J. Conservative or surgical treatment of metacarpal fractures. Unfallchirurg 1993;96(8):427-432.

26. Dumont C, Fuchs M, Burchhardt H, Appelt D, Bohr S, Sturmer KM. Clinical results of absorbable plates for displaced metacarpal fractures. J Hand Surg(Am) 2007;32(4):491-496.

27. Bosscha K, Snellen JP. Internal fixation of metacarpal and phalangeal fractures with AO minifragment screws and plates: a prospective study. Injury 1993;24(3):166-168.

28. Agrawal AK, Pickford MA. Experience with a new ultralow profile osteosynthesis system for fracture of the metacarpals and phalanges. Ann Plast Surg 2006;57(2):206-212.

29. Souer JS, Mudgal CS. Plate fixation in closed ipsilateral multiple metacarpal fractures. J Hand Surg (Eu) 2008;83(6):740-744.

30. Nalbantoglu U, Gereli A, Ucar BY, Kocaoglu B, Degan T. Treatment of metacarpal fractures with open reduction and low-profile plate and screw fixation. Acta Orthop Traumatol Turc 2008;42(5):303309.

31. Fusetti C, Della SDR. Influence of fracture pattern on consolidation after metacarpal plate fixation. Chir Main 2004;23(1):32-36. 